\title{
Colloidal Rhodium: A New Catalytic System for the Reduction of Dibenzo-18-crown-6 Ether
}

\author{
Philippe Drognat Landré, Dominique Richard, Micheline Draye, Pierre Gallezot, and Marc Lemaire ${ }^{1}$ \\ Institut de Recherches sur la Catalyse (C.N.R.S.), 2 Avenue A. Einstein, 69626 Villeurbanne Cedex, France; and Laboratoire de Catalyse et \\ Synthèse Organique (Université Claude Bernard Lyon I). ESCIL, Bâtiment 308, 43, Boulevard du II Novembre 1918, \\ 69626 Villeurbanne Cedex, France
}

\begin{abstract}
The stereoselective hydrogenation of dibenzo-18-crown-6 ether in the cis-syn-cis isomer of dicyclohexano-18-crown-6 ether has been investigated using either supported metal catalysts or colloidal metal particles prepared under phase transfer catalysis conditions. Supported catalysts generally lead to a mixture of isomers with a poor stereoselectivity in cis-syn-cis. In contrast, when phase transfer agents like tertiary amines and ammonium salts were used in a biphasic system, a good selectivity was achieved under mild conditions. The effect of different factors such as the nature and concentration of the phase transfer agents upon the selectivity has been investigated. An increase of the hydrogen pressure to $5 \mathrm{MPa}$ leads to a cis-syn-cis/cis-anti-cis isomer ratio of $95 / 5$. Strong evidence for the heterogeneous nature of the catalysis involved is presented. A mechanism involving the phase transfer agent as a modifier on the surface of the colloidal rhodium particles is proposed.
\end{abstract}

\section{INTRODUCTION}

The hydrogenation of aromatic compounds is well documented in the literature as far as parent hydrocarbons are concerned, but is more scarce as regards the stereoselective hydrogenation of substituted aromatics. Homogeneous catalysts have been used to reduce aromatic hydrocarbons $(1,2)$ under mild conditions. Under more drastic conditions the reduction of aromatic rings can also be achieved using hydrides or dissolved metals as catalysts (3). Hydrogenation with heterogeneous catalysts has probably been the most thoroughly studied method of reducing aromatic compounds (4). However, among the numerous methods described, very few seem to offer a satisfactory stereoselectivity. In a recent review (5), Bartók examines the many factors that may play a role in the stereochemistry of the hydrogenation of aromatic com-

\footnotetext{
'e-mail: richard@catalyse.univ-lyon1.fr
}

pounds. The nature of the metal exerts an appreciable influence on the stereoselectivity of hydrogenation, the selectivity sequence of the different metals depending both on the nature and the position of the substituents. Thus the hydrogenation of ethyl-( $p$-tolyl)-ether yields a cis/trans ratio ranging from 3.7 on Ru and 6.4 on Ir to 12.8 on $\mathrm{Rh}$ and 14.1 on $\mathrm{Pd}$, while the hydrogenation of $o$-methoxyphenol shows the highest stereoselectivity (cis) trans 9) with Rh on alumina. Among other factors, the most important is the reaction temperature. Thus Nishiki et al. (6) have shown that the hydrogenation of $p$-terbutylphenol by sodium borohydride in the presence of rhodium chloride yields a cis/trans isomer ratio ranging from 1 to 2.5 over the temperature range from -35 to $30^{\circ} \mathrm{C}$, and an excess of the thermodynamically more stable trans isomer at higher temperature.

Reduction on heterogeneous catalysts tends to give cis isomers predominantly. Thus Timmer et al. (7), using Rh/ $\mathrm{SrTiO}_{3}$ catalyst for the hydrogenation of $o$-xylene, obtained a mixture of cis- and trans-1,2-dimethylcyclohexane with a cis/trans isomer ratio of 4.7. Solid state reduction of terbutyl-p-phenol in the absence of solvent has been performed with $\mathrm{Rh} / \mathrm{C}$ or $\mathrm{Rh} / \mathrm{Al}_{2} \mathrm{O}_{3}$ by Lamartine and Perrin (8), leading to an excess of the cis isomer of the terbutyl-4-cyclohexanol. Dedov et al. (9) using a rhodiumbased catalyst on polyacrylic acid selectively reduced benzo-crown ethers into the corresponding cis-cyclohexanocrown ethers.

The reduction in biphasic systems in the presence of phase transfer agents as described in the literature has also proved to be effective under mild conditions. The application of this method to the reduction of the aromatic ring was first mentioned by Januszkiewicz and Alper (10), who reduced acetophenone to methylcyclohexylketone in a biphasic catalytic system (water/benzene) in the presence of a rhodium complex, cetyltrimethyl ammonium bromide as the phase-transfer agent and bovine serum albumin as a chirality inducer, since their first aim was 
the enantioselective reduction of the carbonyl group. Then Blum and Vollhardt (11), using a biphasic system (water/1,2-dichloroethane), rhodium chloride, and methyltrioctylammonium chloride (Aliquat-336) as the phase transfer agents, reduced various aromatic compounds, among them 2,3-dimethylnaphthalene, which gives predominantly the cis isomer.

The present work is aimed at studying the reduction of dibenzocrown ether in order to control the stereochemistry of the reaction and to achieve a high stereoselectivity towards a chosen isomer of the dicyclohexylcrown ether. The isomers of dicyclohexyl-18-crown-6 ether (abbreviated as DCH18C6) were proposed as metal extractants from solutions in nuclear fuel reprocessings and they exhibit different complexing properties with various cations. Indeed, it has been recently shown (12) that the extraction constant for plutonium of the cis-syn-cis isomer is three times larger than that of the cis-anti-cis isomer. Since the separation of the different isomers (13) is neither straightforward nor inexpensive, the direct synthesis of each of the isomers by stereoselective reduction of dibenzo-18crown-6 ether (abbreviated as DB 18C6) is worth considering.

The control of the stereoselectivity in such a case is not merely a matter of cis/trans isomerism of substituents around a cyclohexane ring. Since two aromatic rings are present in the reactant (substrate), it is their relative position around the flexible crown ring which has to be controlled as well. Homogeneous catalytic systems which reduce each ring separately are not expected to provide the required control of the relative orientation of the cyclohexyl rings. However, the adsorption of the substrate on a metallic surface may lead to the simultaneous reduction of both rings. Thus if the cis-syn-cis isomer is wanted, then heterogeneous catalysts should be more selective than homogeneous ones and this is the reason why they were tested in the present work.

The reduction of DB18C6 ether is mentioned in the literature, but its stereoselectivity has not been extensively investigated. Thus Pedersen (14) by reducing DB18C6 in the presence of $\mathrm{Ru} / \mathrm{Al}_{2} \mathrm{O}_{3}$ under 70 atm of $\mathrm{H}_{2}$ obtained a mixture of isomers cis-syn-cis and cis-anti-cis in a ratio which was not determined. Laskorin et al. (15) by using Raney Ni obtained a mixture of the five isomers of DCH18C6 which they separated by HPLC and found to contain $16.0 \%$ of trans-anti-trans, $17.5 \%$ of trans-syntrans, $27.0 \%$ of cis-trans, $16.1 \%$ of cis-anti-cis, and $23.4 \%$ of cis-syn-cis. Gurskii et al. 16) used $\mathrm{Ru}, \mathrm{Rh}, \mathrm{Pd}$, and $\mathrm{Pt}$ catalysts supported on carbon to reduce DB18C6 and investigated the factors affecting the chemoselectivity. They observed that hydrogenation and hydrogenolysis were concurrent reactions and that the former was favored by high pressure. However, they did not investigate the stereoselectivity of the reaction.

\section{EXPERIMENTAL}

\section{Materials}

The dibenzo-18-crown-6 ether was purchased from Janssen Chimica. The heterogeneous catalysts came from various suppliers: $\mathrm{Ru} / \mathrm{Al}_{2} \mathrm{O}_{3}$ (5 wt.\% in $\mathrm{Ru}$ ) came from Johnson Matthey, $\mathrm{Rh} / \mathrm{SrTiO}_{3}(0.5 \%)$ from Janssen Chimica, $\mathrm{Rh} / \mathrm{C}(5 \%)$ from Engelhard (3330A Charcoal), and $\mathrm{Rh} / \mathrm{C}(10 \%)$ from Ventron. Rhodium chloride and the other metal salts used $\left(\mathrm{NiCl}_{2}, \mathrm{RuCl}_{3}, \mathrm{PdCl}_{2}, \mathrm{IrCl}_{3}\right.$, and $\mathrm{K}_{2} \mathrm{PtCl}_{6}$ ), as well as the various amines and ammonium salts used, were purchased from Aldrich. The solvents used in the reactions, dichloromethane or 1,2-dichloroethane, were analytical grade from Laurylab. The water used in the biphasic system reduction was HPLC grade (treated by reverse osmosis and deionized).

\section{Reaction}

The atmospheric pressure reactions were carried out under magnetic stirring in a glass vessel connected to a hydrogenation apparatus, and hydrogen consumption was monitored during the course of the reaction. Unless otherwise mentioned the stirring rate was set to the maximum value available with this apparatus, i.e., 1200 r.p.m. Reactions were carried out either at room temperature or at 333 $\mathrm{K}$ using a heating bath. Hydrogenations under sonication were performed with a Branson 2200 apparatus (frequency, $47 \mathrm{kHz}$; power, $205 \mathrm{~W}$ ). The high-pressure reactions were run in a well-stirred autoclave (Autoclave Engineers).

The chemoselectivity of the reaction, defined as the ratio ( $\Sigma$ DCH $18 \mathrm{C} 6$ isomers $) /\left(\sum\right.$ products $)$, was determined either by capillary GC analysis or by ${ }^{1} \mathrm{H}$ NMR spectroscopy.

The mixture of DCH18C6 and hydrogenolysis product obtained after reaction under the conditions where this by-product is at its maximum (GC analysis), i.e., by using quinuclidine as modifier, was separated by elution on a silica column using a heptane/chloroform/methanol (2/4/ 1.7) mixture as eluent. The pure hydrogenolysis product was submitted to the classical analytical techniques and its structure was unambiguously determined as the one displayed in Fig. 1, which means that it results from hydrogenolysis of DCH18C6.

${ }^{1} \mathrm{H}$ NMR; 1.5 (m, 18Ha, b, c, j, k, 1, m); 3 (s, 1 Hs); 3.2 (m, lHd); $3.6(\mathrm{~m}, 18 \mathrm{He}, \mathrm{f}, \mathrm{g}, \mathrm{h}, \mathrm{i}, \mathrm{n}, \mathrm{o}, \mathrm{p}, \mathrm{q}, \mathrm{r})$.

${ }^{13} \mathrm{C}$ NMR; 21.8-22.1 (Cl); 24.15-24.23 (C10); 25.7 (C11); 27.3-27.43 (C2); 32.14-32.24 (C9); 61.69-72.7 (C3, $\left.4,5,6,7,4^{\prime}, 5^{\prime}, 6^{\prime}, 7^{\prime}\right) ; 77.85-78.04(\mathrm{C} 8)$.

MS; peaks at $392,375,293,187,141,126,98$ a.m.u. IR; bands at 3436, 2932, 2858, 1450, $1103,732 \mathrm{~cm}^{-1}$.

Stereoselectivity, i.e., the ratio of the cis-syn-cis and cis-anti-cis isomers of the DCH 18C6, was determined ei- 


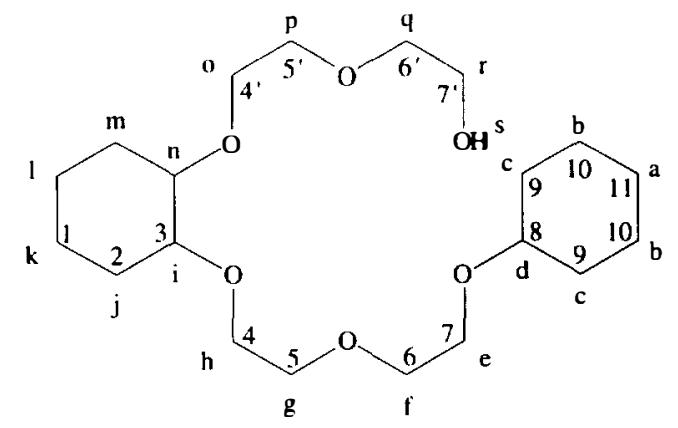

FIG. 1. The main product obtained when the chemoselectivity in DCH18C6 is low.

ther by capillary GC analysis or by ${ }^{13} \mathrm{C}$ NMR using a sequence which allows direct quantification of chemically equivalent carbons with different chemical shifts. The consistency of the stereoselectivity measured with these two techniques was checked and a good correlation was found. The GC analysis was performed with a Duraband $5.5 \%$ diphenylpolysiloxane capillary column from J \& W Scientific using a temperature program from 503 to 573 $\mathrm{K}$ at a $5 \mathrm{~K} / \mathrm{min}$ rate. The pure samples of the two main isomers (cis-syn-cis and cis-anti-cis) were obtained using the uranyl nitrate separation method (13). The ${ }^{13} \mathrm{C}$ NMR determination of the ratio of the DCH18C6 isomers is based on the height of the peak of the carbons of the "crown" ring (17) and was correlated with the GC analysis.

\section{Microscopy}

TEM observations were performed on a JEOL $100 \mathrm{CX}$ transmission electron microscope. The samples were prepared by diluting a few drops of the reaction mixture in about $2 \mathrm{ml}$ of ethanol, sonicating, and then depositing a drop of the solution on a copper grid supporting a thin carbon film.

\section{RESULTS AND DISCUSSION}

\section{Preliminary Studies}

(a) Reduction by supported metal catalysts. Reaction data on heterogeneous catalysts are reported in Table 1 . The reaction conditions of Pedersen (14) on $\mathrm{Ru} / \mathrm{Al}_{2} \mathrm{O}_{2}$ lead to a good conversion in a short time, but the stereoselectivity expressed in the form of the syn/anti ratio is close to one. The use of $\mathrm{Rh} / \mathrm{SrTiO}_{3}$ in an appropriate amount as described by Timmer et al. (7) leads to a complete conversion and a very good chemoselectivity, but the stereoselectivity is also low, and reversed as compared to $\mathrm{Ru} / \mathrm{Al}_{2} \mathrm{O}_{3}$. With the $\mathrm{Rh} / \mathrm{C}$ catalyst, the rate of reduction and the chemoselectivity are generally lower, but the stereoselectivity is noticeably higher. However, none of these

TABLE 1

Heterogeneous Catalytic Hydrogenation and Hydride Reduction of DB18C6

\begin{tabular}{|c|c|c|c|c|c|c|c|c|}
\hline Catalyst $^{a}$ & Metal/DB18C6 ${ }^{b}$ & Solvent & $\begin{array}{c}T \\
(\mathrm{~K})\end{array}$ & $\begin{array}{c}P \\
(\mathrm{MPa})\end{array}$ & $\begin{array}{l}\text { Reaction time } \\
\text { (h) }\end{array}$ & $\begin{array}{c}\text { Conversion } \\
(\%)\end{array}$ & $\begin{array}{c}\text { Chemoselectivityc } \\
(\%)\end{array}$ & syn/anti ${ }^{d}$ \\
\hline $\mathrm{Ru} / \mathrm{Al}_{2} \mathrm{O}_{3}(5 \%)$ & 0.036 & nBuOHe & 383 & 5 & 7 & 98 & $f$ & $57 / 43$ \\
\hline $\mathrm{Rh} / \mathrm{SrTiO}_{3}(0.5 \%)$ & 0.0018 & $\mathrm{EtOH}$ & $\boldsymbol{g}$ & 1.2 & 24 & 0 & - & - \\
\hline $\mathrm{Rh} / \mathrm{SrTiO}_{3}(0.5 \%)$ & 0.097 & $\mathrm{Ch}_{2} \mathrm{Cl}_{2}$ & $g$ & 0.1 & 24 & 100 & 100 & $45 / 55$ \\
\hline $\mathrm{Rh} / \mathrm{C}(5 \%)$ & 0.0175 & dioxane & $g$ & 0.1 & 39 & 3.3 & $f$ & f \\
\hline $\mathrm{Rh} / \mathrm{SrTiO}_{3}(0.5 \%)$ & 0.0018 & none & $g$ & 0.1 & 96 & 0 & - & - \\
\hline $\mathrm{Rh} / \mathrm{SrTiO}_{3}(0.5 \%)^{h}$ & & none & 333 & 0.1 & 40 & 0 & - & - \\
\hline $\mathrm{Rh} / \mathrm{C}(5 \%)$ & 0.0175 & none & 338 & 0.1 & 144 & 33 & $f$ & $f$ \\
\hline $\mathrm{Rh} / \mathrm{C}(5 \%)$ & 0.035 & none & 358 & 0.1 & 164 & 98 & 50 & $68 / 32$ \\
\hline Rh/C (10\%) & 0.035 & none & 333 & 0.1 & 48 & 25 & $f$ & $f$ \\
\hline $\mathrm{RhCl}_{3} / \mathrm{NaBH}_{4}{ }^{i}$ & 4 & $\mathrm{EtOH}$ & $g$ & - & 12 & 42 & $f$ & $f$ \\
\hline $\mathrm{RhCl}_{3} / \mathrm{NaBH}_{4}{ }^{\mathrm{j}}$ & 4 & $\mathrm{EtOH}$ & $g$ & - & 12 & 80 & $f$ & $67 / 33$ \\
\hline
\end{tabular}

${ }^{a}$ Metal loading (wt\%).

${ }^{b}$ Molar ratio.

c ( $\Sigma \mathrm{DCH} 18 \mathrm{C} 6$ isomers $) /(\Sigma$ products $)$.

${ }^{d}$ Ratio of the isomers: cis-syn-cis/cis-anti-cis.

e $n$-butanol has to be distilled twice before use otherwise the conversion dramatically decreases, probably due to the poisoning of the catalyst.

S Not determined.

8 Room temperature.

" This run is the continuation of the proceding one; since no conversion was observed at r.t. the temperature was raised to $333 \mathrm{~K}$.

i $\mathrm{NaBH}_{4}$ /DB 18C6: 10 .

i $\mathrm{NaBH}_{4} / \mathrm{DB}$ 18C6: 30. 
catalysts is stereoselective enough to provide a satisfactory synthetic route to any of the isomers.

(b) Reduction by hydrides. The method described by Nishiki et al. (6) has also been investigated, and the results obtained are reported in the last lines of Table 1 . When a large enough excess of hydride is used, the reduction can be achieved, but the stereoselectivity remains moderate. However, the main drawback of this method is the stoichiometric amount of rhodium requured, since attempts performed with catalytic amounts failed to produce the reduction.

\section{Hydrogenation under Phase Transfer Catalysis Conditions}

The effects of different parameters which may prove effective in controlling the chemoselectivity, the stereoselectivity, and the kinetics of the reaction were investigated.

(a) Nature of the metal catalyst precursor. Different metals of Group VIII were tested under various phase transfer catalysis conditions (Table 2). Few of them are active, although the reduction of the metal salts and the formation of colloidal particles ( 2 to $4 \mathrm{~nm}$ ) were demonstrated in all cases by TEM observation of the reaction mixture. Iridium and platinum give a low conversion, and it is only with rhodium that a high conversion can be achieved within a reasonable time. For this reason the influence of the other factors was investigated only with rhodium-based catalysts.

(b) Nature of the phase transfer agent. The phase transfer agents tested were either a quaternary ammonium salt (Aliquat 336; tricaprylmethylammonium chloride) or various tertiary amines with alkyl chains ranging from ethyl to dodecyl. Two tertiary cyclic amines, quinuclidine, and 1,4-diazabicyclo[2.2.2] octane, were also used. The values of the chemoselectivity and stereoselectivity obtained are reported in Table 3 .

Figure 2 displays the hydrogen consumption as a function of time for the hydrogenation in the presence of the different phase transfer agents. It shows that, except with triethylamine, quinuclidine, or 1,4-diazabicyclo[2.2.2]octane, which are water-soluble, the reaction rate tends to decrease with the increase of the length of the alkyl chain of the amines. In the case of Aliquat 336, the kinetics are more complex. A delay is observed after which the hydrogen consumptions starts at a rate close to the one observed with trioctylamine.

The chemoselectivity increases with the length of the alkyl chain from the triethylamine to the trioctylamine but decreases for the tridodecylamine. This can be explained either by the different basicity of the amines or by their different lipophilicity, both of which depend upon the length of the alkyl chain. The basicity decreases with the length of the chain (cf. Table 3 ) but the $\mathrm{p} K_{a}$ associated with tridodecylamine is not very different from that of trioctylamine, and basicity alone cannot account for the decrease of selectivity observed for dodecylamine. This decrease could be explained by the fact that the longer the chain, the better the stabilizing effect due to hydrophobic interactions, thus leading to more stable metal particles. This thicker layer around the particle makes it more difficult for the substrate to reach the active sites resulting in longer reaction times and more time for secondary reaction to occur.

TABLE 2

Phase Transfer Catalysis: Effect of the Nature of the Metal Catalyst Precursor ${ }^{a}$

\begin{tabular}{|c|c|c|c|c|c|c|}
\hline Metal salt & $\mathrm{M} / \mathrm{DB} \mid 8 \mathrm{C}^{b}$ & T.O.A./ $\mathbf{M}^{b}$ & Aliquat-336/M $\mathbf{M}^{b}$ & $\begin{array}{c}\text { Conversion } \\
(\%)\end{array}$ & $\begin{array}{c}\text { Chemoselectivity } \\
(\%)\end{array}$ & syn/anti \\
\hline $\mathrm{RuCl}_{3}$ & 0.13 & 0 & 0.9 & 0 & 一 & - \\
\hline $\mathrm{RuCl}_{3}$ & 0.13 & 1.26 & 0 & 0 & - & - \\
\hline $\mathrm{RuCl}_{3}$ & 0.05 & 3.5 & 0 & 0 & $\ldots$ & - \\
\hline $\mathrm{RuCl}_{3}$ & 0.07 & 10.8 & 1.4 & 0 & 一 & - \\
\hline $\mathrm{RhCl}_{3}$ & 0.13 & 0 & 0.5 & 100 & 74 & $34 / 66$ \\
\hline $\mathrm{RhCl}_{3}$ & 0.13 & 1.26 & 0 & 100 & 82 & \\
\hline $\mathrm{PdCl}_{2}$ & 0.05 & 3.5 & 0 & 0 & & \\
\hline $\mathrm{IrCl}_{3}$ & 0.05 & 3.5 & 0 & $0.6^{d}$ & & \\
\hline $\mathrm{K}_{2} \mathrm{PtCl}_{6}$ & 0.05 & 3.5 & 0 & 0 & & \\
\hline $\mathrm{K}_{2} \mathrm{PtCl}_{6}$ & 0.13 & 0 & 0.82 & 0 & - & - \\
\hline $\mathrm{K}_{2} \mathrm{PtCl}_{6}$ & 0.13 & 1.26 & () & 13 & 10 & Not determined \\
\hline
\end{tabular}

${ }^{a}$ Reaction conditions: room temperature, atmospheric pressure of $\mathrm{H}_{2}$.

${ }^{b}$ Molar ratio.

"Ratio of the cis-syn-cis/cis-anti-cis isomers.

${ }^{d}$ Mainly the product of the hydrogenation of a single ring of the DB18C6. 
TABLE 3

Phase Transfer Catalysis: Effect of the Nature of the Phase Transfer Agents ${ }^{a}$

\begin{tabular}{|c|c|c|c|c|c|}
\hline Surfactant & $\begin{array}{l}\text { Reaction time } \\
\text { (h) }\end{array}$ & $\begin{array}{c}\text { Conversion } \\
(\%)\end{array}$ & $\begin{array}{c}\text { Chemoselectivity } \\
(\%)\end{array}$ & synlanti ${ }^{b}$ & $\mathrm{p} K a$ \\
\hline 1,4-diazabicyclo[2.2.2]octane ${ }^{c}$ & 24 & 26 & 10 & Not determined & $8.82^{e}$ \\
\hline Quinuclidine $^{c}$ & 5 & 100 & 20 & $35 / 65$ & $10.96^{e}$ \\
\hline Triethylamine ${ }^{c}$ & 12 & 100 & 41 & $53 / 47$ & $10.75^{e}, 9.25^{f}$ \\
\hline Tripentylamine $^{c}$ & 4 & 100 & 57 & $60 / 40$ & $8.79^{f}$ \\
\hline Trioctylamine $^{c}$ & 7 & 100 & 83 & $71 / 29$ & $8.35^{f}$ \\
\hline Tridodecylamine $^{c}$ & 44 & 100 & 65 & $87 / 13$ & \\
\hline Aliquat-336 & 24 & 100 & 86 & $34 / 66$ & \\
\hline$(\text { Aliquat-336 }+ \text { TOA })^{d}$ & 24 & 100 & 86 & $22 / 78$ & \\
\hline
\end{tabular}

${ }^{a}$ Reaction conditions: room temperature, atmospheric pressure of $\mathrm{H}_{2},(\mathrm{Rh} / \mathrm{DB} 18 \mathrm{C} 6)$ molar ratio: 0.14 .

${ }^{b}$ Ratio of the cis-syn-cis/cis-anti-cis isomers.

c (Amine/Rh) molar ratio: 1.2 .

${ }^{d}$ (TOA/Rh) molar ratio: 1.2 ; (Aliquat-336/Rh) molar ratio: 0.42 .

e $\mathrm{p} K_{a}$ of the ammonium salt in water at $298 \mathrm{~K}$, from Ref. (18) for quinuclidine and from Ref. (19) for 1,4-diazabicyclo[2.2.2] octane.

${ }^{f} \mathrm{p} K_{a}$ in $70 \%$ aqueous alcoholic solution at $298 \mathrm{~K}$, from Ref. (20).

When the chemoselectivity towards DCH18C6 is low, i.e., when short alkyl chain amines are used, the main secondary product detected by GC analysis was identified by mass spectrometry and NMR as the alcohol resulting from the hydrolysis and opening of the crown-ether ring (Fig. 1). It is worth mentioning that under the conditions where hydrogenolysis is predominant this is an appropriate route to a class of compounds derived from crownethers by controlled hydrogenolysis.

The stereoselectivity towards the cis-syn-cis isomer also increases with the length of the chain of the tertiary amine, but in contrast to the chemoselectivity, the maximum is observed for the longest alkyl chain, which suggests that the chemoselectivity and the stereoselectivity are governed by different parameters.

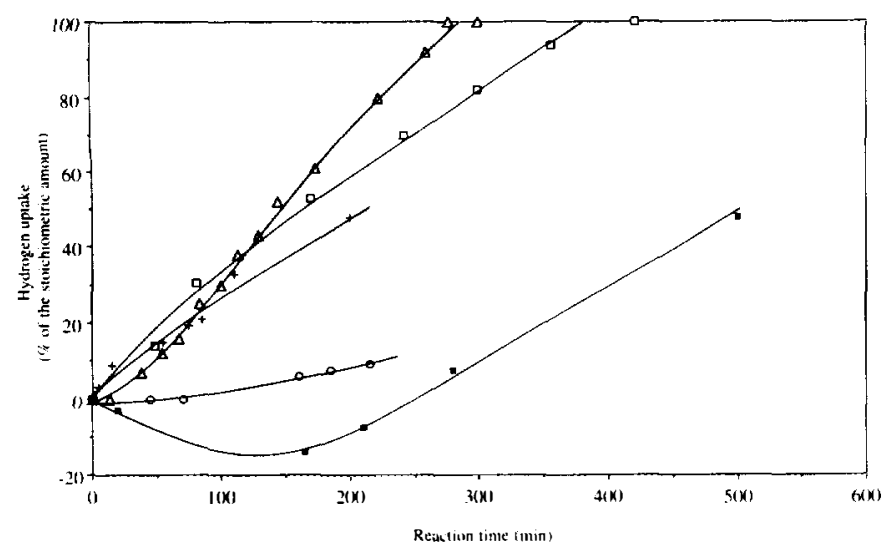

FIG. 2. Effect of the nature of the phase transfer agent on the reduction rate of DB18C6. (+) Triethylamine (TEA); $(\triangle)$ Tripentylamine (TPA); ( $\square$ ) Trioctylamine (TOA); (O) Tridodecylamine (TDA); (ם) Aliquat 336.
It can be seen that the use of Aliquat 336 leads predominantly to the cis-anti-cis isomer. This effect is even larger when a mixture of both trioctylamine and Aliquat 336 is used.

The alkyl chain length of the phase transfer agent has different effects upon the reaction rate, the chemoselectivity, and the stereoselectivity, the best value for each of these properties being reached with different agents. Thus the optimum chain length leading simultaneously to a good chemoselectivity and a good stereoselectivity seems to correspond to a chain of eight carbon atoms. For this reason, the properties of the two phase transfer agents trioctylamine (designated as TOA) and Aliquat 336, were investigated further in order to control the stereoselectivity.

(c) Concentration of phase transfer agents. Different amounts of phase transfer agents were used and the chemoselectivity and stereoselectivity observed are reported

\section{TABLE 4}

Phase Transfer Catalysis: Effect of the Amount of TOA ${ }^{a}$

\begin{tabular}{ccccc}
\hline Run & ${\text { TOA } / R^{b}}^{b}$ & $\begin{array}{c}\text { Conversion } \\
(\%)\end{array}$ & $\begin{array}{c}\text { Chemoselectivity } \\
(\%)\end{array}$ & syn/antic \\
\hline 1 & 0 & 11 & - & - \\
2 & 1.2 & 100 & 82 & $71 / 29$ \\
3 & 3.6 & 100 & 96 & $72 / 28$ \\
4 & 9.9 & 21 & 22 & - \\
5 & 167 & 0 & - & - \\
\hline
\end{tabular}

${ }^{a}$ Reaction conditions: room temperature, atmospheric pressure of $\mathrm{H}_{2}$, (Rh/DB18C6) molar ratio: 0.14 .

${ }^{b}$ Molar ratio.

'Ratio of the cis-syn-cis/cis-anti-cis isomers. 
TABLE 5

Phase Transfer Catalysis: Effect of the Temperature

\begin{tabular}{ccccccc}
\hline Run & TOA/Rh $^{a}$ & $\begin{array}{c}\text { Reaction time } \\
(\mathrm{h})\end{array}$ & $\begin{array}{c}T \\
(\mathrm{~K})\end{array}$ & $\begin{array}{c}\text { Conversion }^{b} \\
(\%)\end{array}$ & $\begin{array}{c}\text { Chemoselectivityc } \\
(\%)\end{array}$ & syn/anti $^{c}$ \\
\hline 1 & 0 & 21 & 298 & 11 & many by-products \\
2 & 0 & 18 & 337 & 16 & many by-products \\
3 & 1.2 & 17 & 337 & 62 & 20 & - \\
4 & 1.2 & 22 & 298 & 100 & 82 & $71 / 29$ \\
\hline
\end{tabular}

Note. (Rh/DB18C6) molar ratio: 0.14 .

${ }^{a}$ Molar ratio.

${ }^{b}$ Determined by ${ }^{1} \mathrm{H}$ NMR.

c Determined by capillary GC analysis.

${ }^{d}$ Determined by ${ }^{13} \mathrm{C}$ NNR.

in Table 4. These results suggest that the optimum value of the TOA/Rh ratio, where the chemoselectivity reaches $100 \%$, is close to 3.6. Since the reduction of rhodium chloride should release 3 moles of $\mathrm{HCl}$ per mole of rhodium, one can assume that 3 moles of amine is used to neutralize the hydrochloric acid formed. The excess (i.e., $0.6 \mathrm{~mole}$ ) is presumably bound to the rhodium and plays a role in the stabilization of the catalytic system, since for high values of the TOA/Rh ratio the conversion decreases drastically. When no TOA is present the reaction still proceeds, but more slowly, and the chemoselectivity is greatly reduced.

(d) Effect of temperature and pressure. The reaction was run at room temperature and at $60^{\circ} \mathrm{C}$; the selectivities observed are summarized in Table 5. Without any phase transfer agent, almost no difference is observed; the reaction proceeds slowly and produces many by-products. When TOA is present, a temperature rise from 298 to 337 $\mathrm{K}$ results in a decrease of the reaction rate. This surprising effect is readily explained by the TEM observation of the colloidal particles after reaction (cf. Fig. 3), which shows that the particles are much larger after a reduction at the higher temperature. Thus the metal specific area is reduced, leading to a rate decrease which is only partially compensated by the rate increase due to the higher temperature. The dramatic decrease of the chemoselectivity is due to side reactions which are more probable at the higher temperature.

Table 6 shows the results of the reaction when it is carried out at high pressure. The rate of the reaction and the stereoselectivity are greatly increased and a syn/anti ratio of $95 / 5$ is obtained with a total conversion after only $42 \mathrm{~min}$, whereas the reduction with the same amount of rhodium requires $10 \mathrm{~h}$ at atmospheric pressure.

Some attempts were made to perform the hydrogenation under sonication. Under stirring, sonication results in a higher rate; however, when no stirring is used, sonication alone leads to no converison. This indicates that the stirring is required for the gas-liquid transfer of $\mathrm{H}_{2}$.

(e) TEM study of the colloidal particles produced after reduction in the biphasic system. As previously mentioned, after the reaction the metal precursor is reduced and is present in the reaction medium as colloidal particles, as shown by TEM. The formation of the metal particles was observed for all the metal catalysts $(\mathrm{Ru}, \mathrm{Rh}, \mathrm{Pt}$, Ir). The formation of rhodium particles was also observed without any DB18C6 in the medium. No systematic study of the particle size was undertaken, since all the observa-

\section{TABLE 6}

Phase Transfer Catalysis: Effect of the Pressure

\begin{tabular}{ccccccc}
\hline Run & Rh/DB18C6 & $\begin{array}{c}\text { Reaction time } \\
(\mathrm{h})\end{array}$ & $\begin{array}{c}\mathrm{P}\left(\mathrm{H}_{2}\right) \\
(\mathrm{MPa})\end{array}$ & $\begin{array}{c}\text { Conversion } \\
(\%)\end{array}$ & $\begin{array}{c}\text { Chemoselectivity } \\
(\%)\end{array}$ & syn/antib \\
\hline 1 & 0.05 & 10 & 0.1 & 100 & 100 & $76 / 24$ \\
2 & 0.05 & 0.7 & 5 & 100 & 100 & $95 / 5$ \\
3 & 0.01 & 1 & 5 & 30 & 43 & - \\
4 & 0.005 & 1 & 5 & 29 & 51 & - \\
\hline
\end{tabular}

Note. (TOA/Rh)molar ratio: 3.6.

${ }^{a}$ Molar ratio.

${ }^{b}$ Determined by capillary GC. 
tions have shown the presence of particles between 2 and $3 \mathrm{~nm}$ in size with two exceptions: (i) reduction of DB $18 \mathrm{C} 6$ conducted without any phase transfer agent and (ii) reduction at temperature higher than room temperature. In these two cases, the particles observed are noticeably larger (cf. Fig. 3).

The observation of metal particles after the reduction of DB18C6 indicates that the reaction proceeds by heterogeneous catalysis. However, it could be argued that the catalytically active species is a rhodium complex and that the metal particles are only formed at the end of the catalytic cycle. In order clarify this point, the Maitlis test (21), generally used to prove the absence of heterogeneous catalysis in homogeneous catalytic reactions, was carried out. The principle of this test lies in the comparison of the reaction rate of a catalytic system and the same system filtered before reaction. Thus, after a reaction was carried out in standard conditions $\left(\mathrm{RhCl}_{3}, \mathrm{TOA}\right)$, the solution was filtered over a graphite powder and the solid collected was then used again for the hydrogenation of a new batch of DB18C6. The reaction rates for the two reactions are similar (cf. Fig. 4); the chemoselectivity ( 89 and $73 \%$ ) and syn/anti ratio $(81 / 19$ and $77 / 23)$ are also close. This is a strong indication that the reaction proceeds by heteroge- neous catalysis. This conclusion is at odds with previous literature data (11), but the substrate involved here is different from the ones studied by Blum and Vollhardt.

Moreover, the positive Maitlis test shows that the reduction of a metal salt in the presence of a phase transfer agent, followed by filtration with a solid support, could be used as a new and simpler way to prepare supported heterogeneous catalyst with stable metal particles of colloidal size.

From the above-mentioned results it is possible to put foward a reaction scheme for this reaction. Our proposal is summarized in Fig. 5 and involves the following steps:

(i) extraction of the rhodium chloride from the aqueous phase by the phase transfer agents via formatiom of ion pairs at the interface of the two phases;

(ii) reduction of rhodium species by $\mathrm{H}_{2}$ and formation of colloidal particles coated by the surfactants;

(iii) exchange between the surfactants and the DB18C6 on the surface of the Rh particles;

(iv) reduction of DB $18 \mathrm{C} 6$ by hydrogen chemisorbed on these particles.

Each step of this mechanism is supported either by experimental evidence or literature data. Step (i) is evidenced by the observation that upon addition of the phase
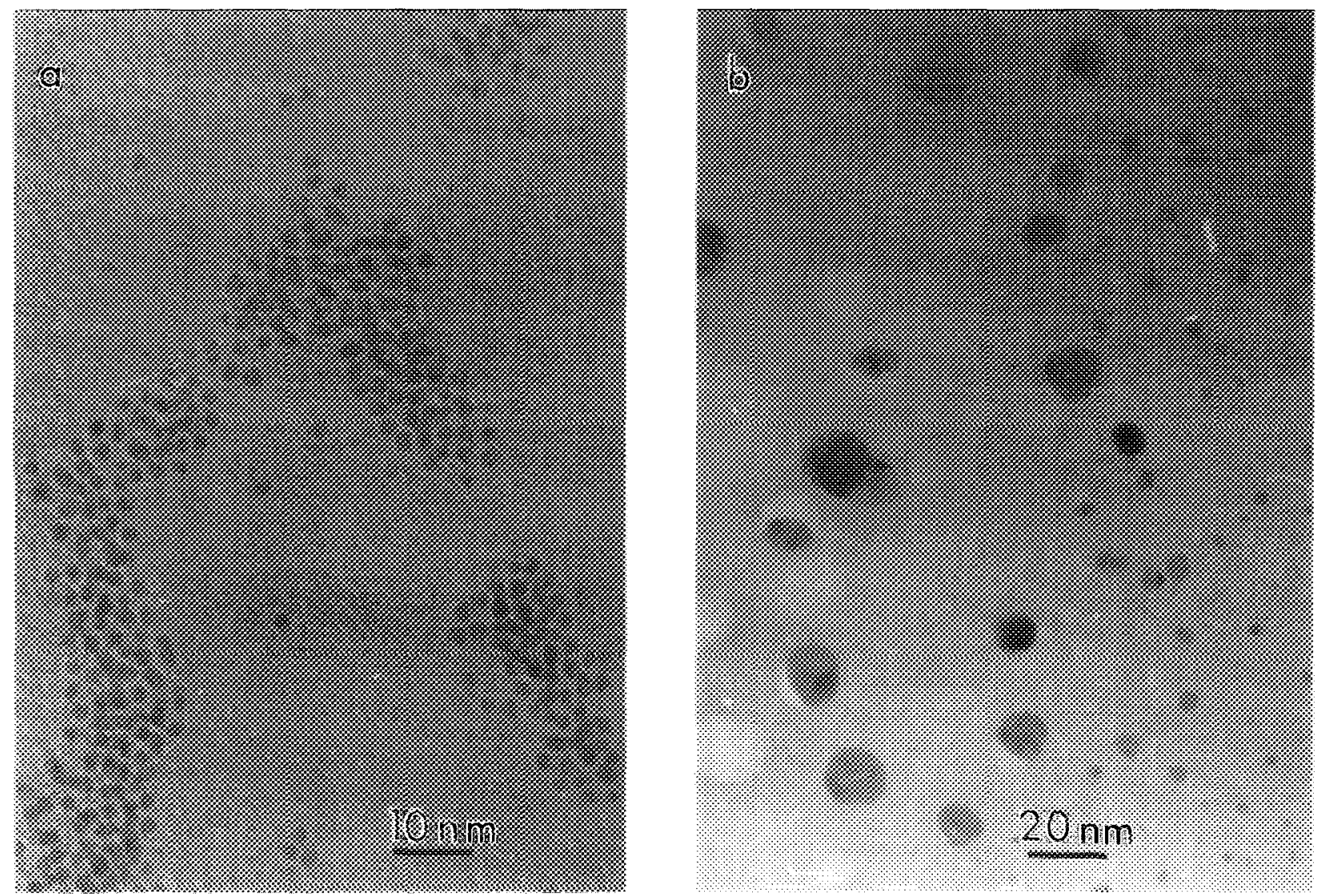

FIG. 3. TEM view of $\mathrm{Rh}$ particles after reduction of $\mathrm{DB} 18 \mathrm{C} 6$ (a) at room temperature and (b) at $60^{\circ} \mathrm{C}$ under the same conditions ( $\mathrm{pH} 2$ : I atm., TOA/Rh: 1.3). 


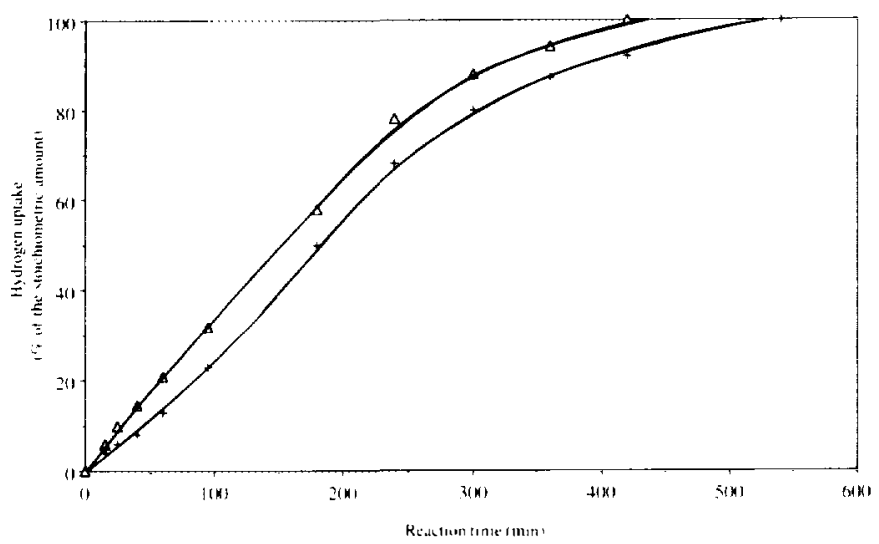

FIG. 4. Maitlis test: comparison of the reaction rate of the $\mathrm{Rh} / \mathrm{TOA}$ system as prepared and of the same deposited on graphite after filtration. (+) First reaction (with $\mathrm{RhCl}_{3}$ as catalyst precursor); $(\triangle)$ second reaction (after filtration on graphite).

transfer agents the initially red aqueous phase rapidly becomes almost colorless, whereas the organic phase turns red. Such ion-pair extraction in biphasic systems has also been demonstrated by Sasson et al. (22).

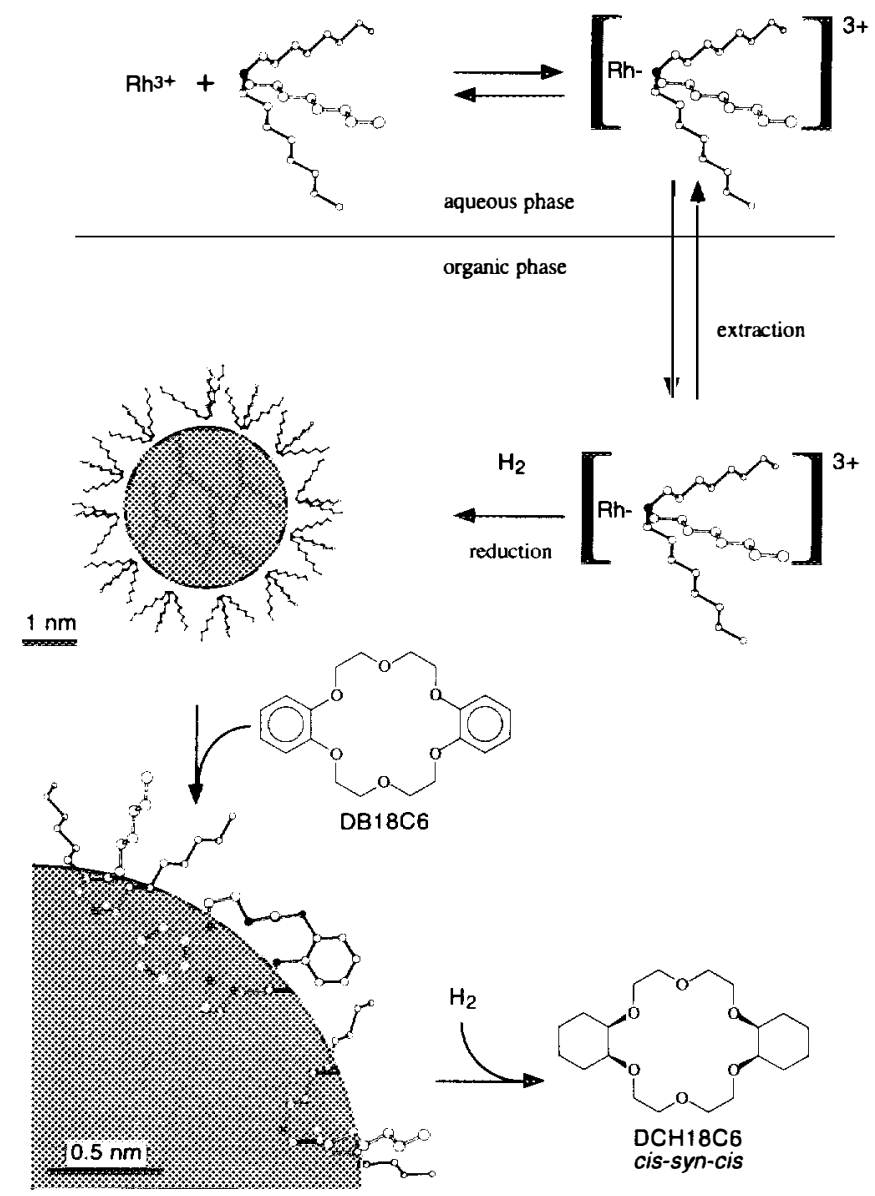

FIG. 5. Tentative mechanism for the reduction of DB18C6 in the presence of a phase transfer agent.
Step (ii) is supported by the observation of the particles by TEM after the reaction. The catalytic activity of rhodium is not due to a soluble complex because the Maitlis test shows that the particles are the active species and since the activity can be recovered after their collection on a support.

We assume that in order to achieve the highest selectivity towards the cis-syn-cis isomer of DCH18C6, the two aromatic rings have to be hydrogenated simultaneously or within a short interval, that is, without any desorption taking place in-between. Such a desorption would lead to the independent hydrogenation of the second ring with a statistical ratio, i.e., to a 50/50 isomer ratio.

The observation that the lowest cis-syn-cis/cis-anti-cis ratios were obtained by using the bases with the shortest alkyl chains is consistent with the adsorption completition at the surface of the particles postulated during step (iii), the partially hydrogenated adsorbed DBI8C6 being displaced by the amines before the hydrogenation of the second ring. In contrast, the weaker bases cannot displace the substrate before it is fully hydrogenated during one stay at the surface of the particles.

This explanation, however, cannot account for the fact that under some conditions an excess of the cis-anti-cis isomer is obtained. This could be interpreted by the existence of an interaction between the adsorbed substrate molecule and a neighboring molecule of the phase transfer agent adsorbed on the surface of the particle. In this case, the selectivity of the reaction is controlled by the supramolecular structure of the catalytic site involving both the metal surface and the surfactant.

This catalytic system is composed of colloidal particles whose properties can be changed by selecting the surfactants which are adsorbed on their surface. The action of the surfactant in this reaction is exerted either as a competitor for an adsorption site or via a direct interaction between the adsorbed substrate and the surfactant. We propose that this method simultaneously involving a metal to achieve the reduction and an additive to lead the reaction towards one of the products is similar in principle with the one developed by Izumi (23) and Blaser et al. (24) who use modifiers for metal catalysts to control their stereoselectivity. Izumi used tartrate-modified Raney nickel to achieve stereo differentiation in the hydrogenation of a variety of compounds, while Blaser et al. used cinchonidine-modified platinum to hydrogenate $\alpha$-ketoesters enantioselectively.

\section{CONCLUSIONS}

This work has shown that the methods described in the literature for the reduction of aromatic compounds involving either heterogeneous catalytic hydrogenation or hydride reduction are not convenient for the stereoselective reduction of DB $18 \mathrm{C} 6$. However, the stereoselectivity 
of the hydrogenation of polysubstituted aromatic systems can be controlled under very mild conditions by phase transfer catalysis. The heterogeneous nature of the catalysis involved was established on the basis of

(i) the TEM observation of the colloidal metal particles formed, and

(ii) a positive Maitlis test, showing that the activity of the system is essentially due to its heterogeneous component.

A mechanism of this reduction under phase transfer catalysis conditions has been postulated which accounts for the experimental observations and assumes the existence of an interaction between the substrate and a modifier adsorbed on the metallic surface of the catalyst.

The results show the potential of using stabilized colloidal metal particles whose catalytic properties can be finely tuned to match the desired selectivity. Indeed, this work adds one more point to the list of catalysts modified to improve the stereoselectivity. Like the tartrate-modified Raney nickel of Izumi and the cinchonidine-modified platinum of Blaser et al., the amine- or ammonium-modified rhodium colloids prove to be effective to control the stereoselectivity, in the present case in the reduction of aromatic compounds. Furthermore, the use of chiral amines or ammonium salts could extend this reduction method to the domain of enantioselectivity.

\section{REFERENCES}

1. Muetterties, E. L., and Bleeke, J. R., Acc. Chem. Res. 12, 324 (1979).

2. Bennett, M., CHEMTECH, 444 (1980).

3. Birch, A. J., and Subbarao, G., Adv. Org. Chem. 8, 1 (1972); Benkeser, R. A. Robinson, R. E., Sauve, D. M., and Thomas, O. H., J. Am. Chem. Soc. 77, 3230 (1953).

4. Rylander, P. N., "Hydrogenation Methods." Academic Press, New York, 1985.
5. Bartók, M., "Stereochemistry of Heterogeneous Metal Catalysis." Wiley, New York, 1985.

6. Nishiki, M., Migataka, H., Niino, Y., Mitsuo, N. and Satoh, T., Tetrahedron Lett. 23, 193 (1982).

7. Timmer, K., Thewissen, D. H. M. W., Meinema, H. A., and Bulten, E. J., Recl. Trav. Chim. Pays-Bas 109, 87 (1990).

8. Lamartine, R., and Perrin, R., in "Spillover of Adsorbed Species" (G. M. Pajonk, S. J. Teichner, and J. E. Germain, Eds.), p. 251. Elsevier, Amsterdam, 1983.

9. Dedov, A. G., Zelenkina, O. A., Zefirov, N. S., Karakhanov, E. A., Neimerovets, E. B., Samoshin, V. V., Subbotin, O. A., and Tskhai, L. E. A., Dokl. Akad. Nauk SSSR 306, 876 (1989).

10. Januszkiewicz, K. R., and Alper, H., Organometallics 2, 1055 (1983).

11. Blum, J., and Vollhardt, K. P. C., J. Mol. Catal. 34, 221 (1986).

12. Lemaire, M., Guy, A., Chomel, R., and Foos, J., J. Chem. Soc., Chem. Commun., 1152 (1991).

13. Guyon, V., Drognat Landré, P., Guy, A., Foos, J., and Lemaire, M., Chem. Lett. 723 (1992).

14. Pedersen, C. J., Org. Synih. 52, 66 (1976).

15. Laskorin, B. N., Yakshin, V. N., and Federov, A. T., Zh. Anal. Khim. 39, 1115 (1984).

16. Gurskii, R. N., Istratova, R. V., Kirova, A. V., Kotlyar, S. A., Ivanov, O. V., and Luḱyanenko, N. G., Zh. Org. Khim. 24, 607. (1988).

17. Guyon, V., Dallery, L., Guy, A., and Lemaire, M., Nouv. J. Chim. 17, 577 (1993).

18. Grob, C. A., Simon, W., and Treffert, D., Angew' Chem. Int. Ed. Engl. 12, 319 (1973).

19. Paoletti, P., Stern, J. H., and Vacca, A., J. Phys. Chem. 69, 3759 (1965)

20. Borrows, E. T., Hargreaves, B. M. C., Page, J. E., Resuggan, J. C. L., and Robinson, F. A., J. Chem. Soc. 201, (1947).

21. Hamlin, J. E., Hirai, K., Millan, A., and Maitlis, P. M., J. Mol. Catal. 7, 543 (1980).

22. Sasson, Y., Zoran, A., and Blum, J., J. Mol. Catal. 11, 293 (1981).

23. Izumi, Y., Adv. Catal. 32, 215 (1983).

24. Blaser, H. U., Jalett, H. P., Monti, D. M., Reber, J. F., and Wehrli, J. T., in "Heterogeneous Catalysis and Fine Chemicals" (M. Guisnet, J. Barrault, C. Bouchoule, D. Duprez, C. Montassier, and G. Pérot, Eds.), p. 153. Elsevier, Amsterdam, 1988. 